\title{
GROWTH OF COMPUTING TECHNOLOGY FOR EDUCATION IN INDIA
}

\author{
Rakesh Mohan Bhatt \\ HNB Garhwal University, India \\ Email: rmbhatt@edumail.nic.in
}

\begin{abstract}
Education and expansion of education have been the main task of any society. Owing to its heterogeneity and pressure from a population of over one billion, India needs more rigorous attempts to elevate its education status; though some of its parts are well socially developed. Further, with the deployments of computers in the educational institutions and infrastructural developments to meet the computer enabled services, remarkable growth has been observed. While discussing the status of the growth of computing technology for education, emerging computing and infrastructural environments and other related developments have also been discussed in this paper.
\end{abstract}

Key words: Computing technology; India; Education

\section{INTRODUCTION}

History of Indian education has witnessed several endeavors and many changes in the educational system. The ancient Indian educational system was based on the Gurukul concept where the mode and contents of learning were decided by the teacher, the Guru himself. At that time we did not have any kind of professional or job centric education. During India's preindependence period, a separate Department of Education was established in 1910. At the time of independence on 15th August 1947, India had a population of 350 million. A Ministry of Education was established on 29th August 1947. Between the years 1950-1951 to 2001-2002, the growth of enrollment in primary, upper primary, secondary and senior secondary has 
increased by 6,14 and 20 times. Similarly, the number of colleges for general education and professional education has also increased by about 24 and 12 times respectively; while the number of universities has increased by 10 times during the period 1950-1951 to 2001-2002 [1]. The percent of education expenditure to GDP in 1991-1992 was 0.64 only which is now 4.04 in 2001-2002.

Influenced by the advancement in science and technology, educational institutions encourage the use of new learning modes to achieve their goals. Computing in education is increasingly becoming a vital tool and computers have dominated its role. This is the main focus of this paper besides discussing the phenomenal growth of other media/technology, viz. radio, television, video, teleconferencing, Internet, and communication infrastructure.

\section{THE PHENOMENAL GROWTH IN COMPUTING TECHNOLOGY}

Computing technology in education can be understood as comprised of different media and technology to interact with society for educational purposes. It may cover one or more of: a) Media and AV communication, e.g., alternative instructional delivery systems such as Radio, ETV, etc.; b) Training tools like CBT (Computer Based Training) and CAD (computeraided design), etc.; c) Instructional delivery and management via computers and computer-based systems, e.g. CAI (Computer Assisted Instruction) etc.; and d) Internet/web based education.

The following sections discuss the beginning of the computing era in India, its entry in the education systems and other developments.

\subsection{The Foundation Era}

The first computer came to India in 1965 and was used in the Indian industry. This entry was observed as a replacement of the mechanical tabulators [2]. Education in computer science began at Indian Institute of Technology, Kanpur, and the first Ph.D. graduated in 1969. About 2000 working professionals were also produced by this institute during 1970s. Further, during this period, for the first time in India, Electronics Corporation of India Ltd. (ECIL) designed a machine TDC-12 (Trombay Digital Computer-12), but could not provide its viable stay in the market [3]. For promoting education in information technology (IT), post B.Sc. and Master of Computer Applications (MCA) were recommended by the man 
power committee which became functional around 1980s. The design of mini-computers by Indian companies also accrued during this period [4]. During 1980s, the demand for IT education and growth in software industry were observed. Around 1990s, the general public saw the application of computers in a broader way when Computer Maintenance Corporation Ltd. (CMC) computerized the reservation system of the Indian railways; the happening allayed the fear of unemployment as conceived earlier [3]. During this period, Indian software professionals got world-wide recognition. In 1995, internet was available access for the Indian public. After 1996, each year, about $45 \%$ annual growth of computer PCs was observed. In August 1997, Indian economists observed (Computer@home, Feb. 2001, Cyber Media (India) Ltd., www.dqindia.com) the knowledge-based industries at a new threshold in India that grew faster than any other infotech industry in the world. Since then many milestones have been crossed.

\subsection{Primary and Secondary Education}

Presently, the formal education system covers over 106 million children at primary stage, 39 million at middle stage and 23 million at secondary stage [5]. For diffusion of information for education, on 28th October 1961, televisions were provided in the schools, for the first time in India. The satellite instructional television experiment (SITE) was conducted [6] from August 1975 to July 1976. After its success, many satellites were launched and direct broadcast proved [7] cheaper than the conventional system. Further, countrywide classroom programs were started [8] on 15th August 1984. CLASS (Computer Literacy and Studies in Schools) and CLAP (Computer Literacy and Awareness Programme) were also launched during 1984. A total of 12,000 such Computers were received and distributed to Secondary and Senior Secondary Schools through State Governments. "Operation blackboard" was also launched in 1987 and 23000 schools were covered. For the development of education in its entirety, the updated Programme of Action (POA) in 1992 under the National Policy on Education (NPE), 1986, enunciated a comprehensive framework. Following this, decentralization in education was done through the local bodies - the Panchayat Raj institutions. To promote quality and modern education, 503 Jawahar Navodaya Vidyalayas (a kind of special schools from VI to XII level) for the rural children, were opened in almost every district of the country. NPE also emphasizes the use of multimedia packages and related technologies. During 1995-1996, National Council of Educational Research and Training (NCERT) also conducted an experiment on audio and video conferencing. Other experiments using the computing technologies have recorded positive effects on motivation among the variety of target groups of 
the learners.

The Project CLASS was further continued under governmental five year plans, under which, 2598 schools having BBC Micros were equipped under this project. In addition, 2371 schools were also covered with new hardware and services. Further, to address the new vision and long-term objectives, the scheme was stopped in 1996-1997 and renamed as CLASS 2000. The revised scheme started in 2001-2002 and proposed to choose 10,000 schools to provide computer literacy and another 1000 schools to provide computerbased learning. Under the concept of Smart Schools, choosing 100 schools as a pace setters, was envisaged. Therefore, under this total literacy campaign (TLC) during last year in 2003, out of total 588 districts in the country, more than 550 districts have been covered and the rest are in the ongoing phase [9].

\subsection{Higher Education}

For the higher-level education, University Grants Commission (UGC) is the apex body vested with the responsibility of development of higher education in the country. It has been providing financial assistance to all Central, State and Deemed Universities, both under Plan and Non-Plan schemes, for improving infrastructure and basic facilities. Presently, 294 universities/ institutions in India have 13150 affiliated colleges, about 8.8 million students, and 430000 teachers [1]. About 142 university libraries are on the way to computerization [10]. In the late 1970s, RECs (regional engineering colleges) and private colleges were opened [11]. To further boost the growth of technical higher education, in 1992, AICTE (All India Council for Technical Education) and some other institutions were established. It was decided on 1 November 2001, to establish "A UGC Network" for providing information connectivity to each university, UGC has now started the UGC INFONET for the virtual enhancement of the academic structure. By the beginning of 2004, about 183 universities are being covered under this network.

Need of continuing education and for equal opportunity for higher education, of the developments in the field of information communication technology and of enhancement of infrastructure for communication, have generated excellent opportunity. In view of this, Indira Gandhi National Open University (IGNOU) established during late eighties, offers 72 programmes and its cumulative enrolment in 2001 stood at over 1.2 million. The University has created a network of student support-structure, with 46 regional centers and 765 study centers all over the country. The University has also created a media network and teleconferencing system to electronically link all distance-teaching institutions in the country. Many 
earlier departments of correspondence courses in various universities have been converted into independent open universities during the ninth plan period. There are, at present, nine open universities in the country, all founded by different states during the nineties.

To measure the role and impact of computing technologies, some significant experiments were conducted. Some of them are discussed here. IGNOU conducted a Cable TV network programme in April 1993 through interactive mode [12], another in October 1993 covering its 10 regional canters through teleconferencing mode [13]. The programme recorded a positive response from the participants. Another telecourse was conducted [14] over television by Consortium for Educational Communication (CEC) between 15-24 December ember 1994 The revised educational technology scheme in 1987 gave emphasis over TV and audio program productioncapabilities and its wider access on TV and radio-come-cassette players (RCCP).The Central Institute of Educational Technology (CIET) started Class-2000 on Door-Darshan channel on 50:50 basis [15].

To supplement the face-to-face academic counseling through All India Radio (AIR) and over 1620 radio lessons were broadcasted until 2000. Interactive radio-phone started on 23rd April 2000. Telecast of the Video lesson took place from 1st November 1999. Interactive teleconferencing, a part of education technology conducted on 14 and 15 March 1999 and in the year 2000 over 20 such conferences took place [16].

\subsection{Infrastructural Developments}

Telecommunications is one of the prime support services needed for rapid growth and modernization of various sectors of the economy. It has become especially important in recent years because of enormous growth of Information Technology (IT) and a significant impact on the rest of the economy. India is perceived to have a special comparative advantage in IT and in IT-enabled services. During the Ninth Plan period, a record growth rate of telecom services was achieved in the country. The network (equipped capacity) grew at an average rate of about $22 \%$. Current efforts involve approval of the Convergence Bill 2000; Internet Telephony has also been opened from 1st April 2002. In 1995, India started its cellular phone service and now the base of the cellular network has grown only 0.34 million connections to 6.43 million connections by the year 2002. As per the Telecom Regulatory Authority of India (TRAI), the mobile subscriber base is expected (www.trai.gov.in) to grow from 30 million of the year 2003 to 55 million mark in 2004. Growth of the tele-density has become 4.4 as of 31 March 2002 (tripled as on 1997). It is envisaged that the country need to 
achieve an overall tele-density of 9.91 by the end of the Tenth Plan i.e. March 2007 [17].

In the present status of Telecom services Network, the total of fixed telephone connections is 38.60 million. Internet Connections are 4 million now [18]. Presently, 17 million people are using the Internet [19]. 70 million households have TV and 35 million have the cable connection.

\subsection{Initiatives in IT sector}

Government notification on 25th July 1998 recommended 108 points of improvement [20] by the national task force on IT and software development which was set up on 22nd May 1998 to formulate the draft of a national informatics policy. The WG on IT for masses [21] was constituted by government on 10th May 2000. The group deliberated on issues like infrastructure and service, electronic governance, education, and mass campaign for IT awareness. Among the 16 points, the education related issues are: IT in government, Citizen IT interface, IT spread and IT awareness. The Media Lab Asia project has also been initiated in 2001 to make IT popular for the masses. Upgradation of the Education and Research Network (ERNET) connecting various universities and regional engineering colleges (RECs) through a high speed network is on the way. Further, for bridging the digital divide, 487 Community Information Centers at the block headquarters in the northeastern states and Sikkim is being set-up. The Ministry of IT has envisaged in its IT Action plan increase 100 million internet connections by 2008 with a ratio of one PC per 50 people. To provide legal recognition for transactions through electronic data interchange, the Information Technology (IT) Act, 2000, has already been enacted. Spending for IT is about $0.7 \%$ of GDP. As per NASSCOM [22], spending for IT was increased by $24 \%$ during 2003 . With the growth of over $60 \%$ in the ITES sector during the year 2002-2003, NASSCOM [23] estimated its growth of US \$21-24 billion by 2008 .

In view of the on-going development, it is noteworthy that there has been significant increase in the government plan outlays for computer/internet connections and its training in education; telecommunication, information and broadcasting sectors, so these efforts will certainly enhance the computing technology for education in India. In the following section, the efforts which accelerate the growth are discussed. 


\section{ACCELERATIVE EFFORTS}

Interestingly, computers have been in use for about 25 to 30 years in India but only by English educated citizens. In India, 18 languages and 10 different scripts are recognized and about 1650 dialects used in the various states. This may be one of the reasons for the low penetration rate of PCs which is only 6 per 100. To improve this situation to date, ISCII (Indian Script Code for Information Interchange) and Unicode standards have been evolved [24] to allow the simultaneous use of English and script alphabets, and to encode the multilingual text respectively. During the tenth five year plan (2002-2007), Vidyavahani and Gyan Vahini projects were started [25] on a pilot basis for providing connectivity to government senior secondary schools and higher learning institutions, respectively. A portal developed under the Vidhyanidhi project [26] helps doctoral research through a pedagogic journey, very exiting and rich with its facilities, resources and tools. $25-30 \%$ of the doctoral theses in India are in local languages, Vidyavahini uses Unicode for its digital library of local language e-theses. Another project, Gyan Nidhi [25] aims to develop a 1 million page multilingual parallel corpus in English and 12 Indian languages.

Keeping in view the current demand for IT and computerization, a major thrust has been noticed to familiarize students with information technology. The State Governments are preparing Computer Education Plans (CEP). The scheme "ICT in Schools" include - i) strengthening and reorientation of staff, ii) digitization of SIETs' video and audio cassettes on the basis of need assessment and in partnership with NGOs, iii) web/internet based education to be managed by the SIETs, and iv) production of video and audio cassettes after assessing the demand.

Many web-sites offer open on-line debates on how to popularize the education among children. For example, Vidya On-line [27] invites teachers, researchers, academics and concerned individuals to participate in the online forum, particularly on issues related with the ICT for education in primary education.

The Act 2002 was enacted for free and compulsory education as a fundamental right for all children between 6-14 in December 2002. To promote computer literacy, the department of IT has also constituted computer literacy excellence award for schools. More than 1000 pilot projects are running by GOI for spreading IT among the masses. About Rs. 14550 million have been spent in these projects [28]. The success rate is estimated at $40 \%$.

To further remove the drawback present in the education system and to elevate its status, national education policy was updated in 1992, decentralized education, emphasized micro-planning, and Village Education 
Committees. Afterwards, many innovative programmes are implemented like the Special Orientation Programme (SOP) which was the first experiment using interactive TV conducted from 7-13 January 1986 and was found [29] in favor of the learner. Further initiatives are Sarva Shiksha Abhiyan at the national level and at state level are Lok Jumbish, Bihar Educational Project, and Andra Pradesh Educational Programme etc. In these programmes, during 1992-1993 to 1995-1996, Rs. 8163 million and during 1996-1997, Rs. 2910 million were spent. The aim, to maintain the presence of about 200 million children throughout their courses and to sustain their integration in further classes, is yet to be achieved. To send every child to school during the year 2003 Rs. 54500 million were sanctioned and in the current year Rs. 30000 million has been allocated [30].

IGNOU has established the Distance Education Council (DEC) to act as the nodal agency for the distance education system at the tertiary level. The university has adopted an integrated multimedia instructions strategy consisting of print material and audio-video programmes, supported by counseling sessions at study centers throughout the country. A dedicated Satellite TV Channel, Gyan Darshan, managed by IGNOU, is beaming educational programmes from school to tertiary level 24 hours a day. Preparations are on to launch 40 FM educational radio channels (Gyan Vani) in the country under a Memorandum of Understanding with Prasar Bharati. During the Tenth Plan, IGNOU would set up open universities in States, which presently do not have them, and to expand the activities of Gyan Darshan and Gyan Vani in different parts of the country. The target is to extend the coverage of open learning systems to backward regions, remote inaccessible areas of the northeast, and low female literacy blocks in some of the eastern states. Courses have also been offered through the virtual campus of IGNOU [31] and Tamil Virtual University. Some recent experiments are being conducted to measure its role and dimensions. Some of them are discussed in the following section.

\section{OTHER EXPERIMENTS}

In an attempt at IIT Kanpur, a teleconferencing tool [32], consisting of three components, the teacher, the students' console and the lecture manager, is designed to allow the teacher to present lectures using text, viewgraphs, graphics, audio and video files. Interaction can take place via a whiteboard or by speaking up. In the learning environment, method of transmission of information is the most important element as a content-carrier between teacher and student. To enable the virtual environment, where the teacher/student is projected distantly, a software prototype design - Virtual 
Lecture Hall, have been developed. This is a part of the project Virtual Classroom at IIT Kanpur that aims to provide virtual education and training, preserving simultaneously the norms of the lecture hall. Designing a virtual learning environment for situated learning, IIT Kharagpur, has evolved a system [33] in the form of the ElNet-3L (Electronically Networked LifeLong-Learning) project which disseminate the course in the Tutored Video Instruction (TVI) mode through the 'Collaborative Group Learning' format. It is also reported [34] to use the upgraded communication switches and facilities to enhance the course effectiveness. Computer-based and computer mediated collaborative learning model are also being developed at the ER and DCI, Calcutta [35], to provide computer assistance for remote learning based on the principles of Instruction Design propagated by Robert Gagne. Very recently, a satellite, EduSet, has been set [36] to launch in 2004 with aims to educate the Indian masses from all streams of life.

\section{IMPLICATIONS}

Several of the above mentioned experiments have been observed. Their implications will be discussed here. One of the success stories is from Gyandood project [37]. It was implemented in the Dhar district of MP state, where cyber café-come-cyber offices for masses as well as social engineering through IT were introduced. Its success was adjudged on many dimensions and the project received the prestigious award- Stockholm challenge - IT Award-2000 on 6th June 2000. In another project, the Simputer Trust [38] a non-profit trust created basically to develop technology that will help take information technology to rural areas has been started. It has developed "Simputer", a new cheap computer for the poor. Its initial target is India. The visually impaired can use the video camera to scan text. The optical character recognition software converts it into text that a computer can understand, and then text software converts that text into audible speech. Thus a blind person could now read.

Indian industries felt that bridging up the existing digital divide exists in the community will in turn give success to their business. Past years have seen many fruitful initiatives in IT literacy campaigns. The detail stories of the companies like IBM, NIIT, Aptech, Infosys, Xansa, Intel, Cisco and Texas Instruments can be found on-line [39], where IT literacy has been discussed as the new social cause.

Set-up in 2003, the INDEST Consortium (Indian National Digital Library in Engineering Sciences and Technology), has subscribed to over 5000 electronic journals [40] and any institute can become informational rich in promoting advances in teaching and learning process. 


\section{DISCUSSION}

As a result of the ongoing effort, significant results can be noticed e.g. during 1961 to 1996, fall in drop-out rates from $70 \%$ to $40 \%$ have been found in the primary schools children. In 1991, the literacy rate was $52.21 \%$ and made up to $65.37 \%$ in 2001. UNESCO reports also shows $30 \%$ increase to access the basic education, which might show the impact of the input of computing technology in education.

Measures to increase enrolment, including that of the disadvantaged sections, in the higher education system would be given utmost attention. It is hoped that role of computing technology can give a raise of $4 \%$ in the enrolment of the age group 18-23 as envisaged [41] during the years 20022007. A major catalyzing factor has been the dynamism and enthusiasm of the Government in the planning and deployment of Information Technology (IT) in schools. Institutions such as UGC, IGNOU, and CIET have started to transmit the curriculum on Doordarshan channel, but the ETV's education specific programmes do not meet the demand of the students [42]. In changing the instruction design in the current paradigm, IT means can have a major impact on teaching and learning processes.

\section{CONCLUSION}

The on-going implementation of the computing technologies for education could create a suitable learning environment, required for the group as well as student-centric learning environment. One of the main advantages of such an environment is the flexibility that leads to make the size to fit into one's learning needs or acquisition of knowledge. Therefore, educational institutes should meet the required changes/ upgrading to provide the need based computing technologies. Many efforts have established this technology as a self-support system to meet the varied requirements and to enhance the quality of educational practices by increasing self-initiation, self-motivation, self-reliance etc. Thus, we hope, in the bright sunny years to come, this silver lining of the computing technologies will grow in many folds in length and width in finding new education possibilities by providing new openings and opportunities to learn.

\section{ACKNOWLEDGEMENTS}

I sincerely acknowledge the valuable suggestions from the HCE Program Committee and others to reconstructing the paper in the present shape. I also 
sincerely acknowledge the encouragement received from N. Natarajan, ViceChancellor, HNB Garhwal University, and Srinagar. I am also grateful to D. R. Purohit for his careful proof-reading. I am also grateful to the Computer Society of India for their support.

\section{REFERENCES}

1. http://www.education.nic.in/htmlweb/higedu.htm.01-10-2001. National Infomatics Centre.

2. Prasad, Kamta and Verma, Pramod. Impact of Computer on Employment, New Delhi: McMillan Co., 1976.

3. Rajaraman,V. "IT in India-A Retrospective (1965-99)".CSI Communication,Jan.2000:.914.

4. "Report of the panel on computer man power development (Chairman Prof. V. Rajaraman) Electronics information and planning". Information and planning group, Government of India. 8. November1980:.55-70.

5. Elementary Education.01-10-2001. National Informatics Centre. 23-3-2004. http:// www.education.nic.in/htmlweb/main.htm/eleedu 1.htm.

6. Sharma ,D. K..." Distance education systems of the future". University News .24(42).( 1986): 55-57.

7. Nath, Ram." Space technology in the third world and towards strategy of self reliance". University. News. 21(1).(1983):.2-5.

8. Booklet on UGC countrywide classroom,.

9. Literacy in India.23-07-2003.Commonwealth of Learning. 30-12-2003. http://www.col.org /literacy/india/htm.

10. http://web.inflibnet.ac.in.25-02-2004.Informational Library Network, An Autonomous Institute of UGC

11. Dutta, Rattan K ."Bridging order in chaotic IT education" .CSI Communication, January $2004: 5-9$.

12. Chaudhari,Sohanvir S.,and ihari, Sham. "Modasa experiment: distance teaching through cable TV". IJOL 3(1)1994:24-28.

13. Sahoo, P. K., 1994. "Teleconferencing in distance education : IGNOU experiment". IJOL 3(1)(1994):31.

14. New communication and information technologies ( a tele-conference course package) CEC, New Delhi. 1994.

15. Khullar, K. K. "Electronic programme - missing target groups". The hindustan times, news paper. 8 August 1995.

16. Khanam, Shakeela. "Learning in future", University News, 8(47), 2000.

17. Planning Commission. 10-05-2003. National Informatics Centre. 23-3-2004. http:// planningcommission.nic.in/plans/planrel/fiveyr/welcome.html.

18. Amar Ujjala News paper. 04 Feb. 2004.

19. Zee News Channel. 25-09-03. 8.30pm.

20. Information Technology.03-07-2001.Ministryof IT, Government of India. 23-2-2004. http://it-taskforce.nic.in.

21.IT for Masses. 24-6-2000. National Infomatics Centre.23.2.2004. www.itformasses.nic.in.

22. Express Computer,.13( 44). 2003.

23. Singh, Nikita, "IT careers for you”. CSI Communication, January, 2004:13-16. 
24. Fichardo, Chris Ann. "The A AA E of Indic computing", Express Computer, 15 Sept. 2003:14-16.

25. http://www.cdacindia.com. 12-9-2003. Ministry of IT, Government of India.

26.Urs, Shalini R.Vidyanidhi, "Digital Library and E-Scholarship", Portal.25-09-2003. http://www.vidyanidhi.org.in

27. Discussion Forum. 27-12-2003. Dept. of Education, Ministry of Human Resource \& Development. http://www.vidyaonline.net/

28. Latest Trivia.07-11-2003. www.bhashaindia.com/trivia/trivia.aspx

29. Das,NK. "Reaction of primary school teachers towards training through interactive TV". IJOL, 6(2)(1997):.77-90.

30. Bamjai, Kavery. India Today. Feb. 17-23, 2004:44.

31. Indira Gandhi National Open University. 24-07-2003. http://www.ignou.edu

32. Manjunath, D, Sale, Sandhya V. and Tripathi, Madhu."Remote Tutor - A multimedia Teleseminaring Tool for an Internet"., Int'l conf. on Collaborative and Networked Learning, 16-18 Feb. 1998:58-62.

33. Komaragiri,Vihari V. and Sanghi Dheeraj, "Designing a virtual learning environment for situated learning", Int'l conf. on Collaborative and Networked Learning. 16-18 Feb.1998:.71-75.

34. Bhattacharya, B and Roy ,A. K. "Off-Campus Distance Education through Electronically Networked Study Centre". Int'l conf. on Collaborative and Networked Learning. 16-18 Feb. 1998: 45-49.

35. Saha, Amiya Baran, SenGupta ,Suparna, and Jain,Deepak."Computer Assisted Learning: A New Approach by ERandDCI Calcutta" National Centre for Software Technology. http://www.ncst.ernet.in/vidyakash2002/extra-papers/Computer_Assisted_Learning-

A_New_Approach.doc

36. National Institute of Eduaction \& Planning. 22-05-2003. http://www.niepaonline.org /whatsnew.htm

37. Rajora, Rajesh and Vyas, Nitesh. "Gyandoot”.CSI communication.Feb. 2001:13-14.

38. India's simple computer for poor.24-09-2001.British Broadcasting Company.26-11-2004. http://news.bbc.co.uk/1/hi/sci/tech/1560771.stm.

39.Jasrotia, Punita.IT literacy - the newsocial cause. http://www.expressitpeople.com /20020318/cover.html. 18March.2002.

40. http://paniit.iitd.ac.in/indest. 25-9-2003. Indian Institute of Technology.

41. http://www.ciet.nic.in/etissues.html. 23-05-2002. Central Institute of Eduactional Technology.

42. Rai, K and Bhattacharya, P.K. "Implications of IT for teacher education and research". http://www.ciet.nic.in/etissues.html. 03-08-2002.Central Institute of Educational Technology. 